\title{
Prognostic factors in Polish patients with BRCA1-dependent ovarian cancer
}

\author{
Wiktor Szatkowski ${ }^{1}$, Paweł Blecharz ${ }^{1}$, Jerzy W. Mituś2, ${ }^{2,}$, Marek Jasiówka $^{4}$, Elżbieta Łuczyńska ${ }^{5}$, \\ Jerzy Jakubowicz ${ }^{6}$ and Tomasz Byrski ${ }^{7}$
}

\begin{abstract}
Background: Treatment outcomes appear to be better for ovarian cancer (OC) patients carrying the BRCA1/2 germline mutation than for patients with sporadic OC. However, most published data are for North American, British and Jewish populations. There have been very few studies on treatment outcomes in Central and Eastern European patients with OC. The aim of this study was to analyse prognostic factors in Polish patients with BRCA1-dependent OC (BRCA1-OC).
\end{abstract}

Methods: The records of patients with OC treated with surgery and chemotherapy at the Centre of Oncology in Kraków, Poland, between 2004 and 2009 were reviewed. Based on family history, a group of 249 consecutive patients fulfilling the criteria for risk of hereditary OC were selected and tested for the germline BRCA1 mutation. Response to combination therapy (surgery and chemotherapy) in the BRCA1-OC group was assessed based on clinical examination, imaging and serum CA125.

Results: Germline BRCA1 mutations were detected in 69 of the 249 patients, but three of these patients failed to complete the study. Finally, 66 patients with BRCA1-OC were included in the study group. The median age of the study patients was 49.5 years. All had undergone primary or interval cytoreductive surgery and chemotherapy. Progression occurred in 48 (72.7\%) of the 66 patients and median time to progression was 20 months. The 5-year overall survival rate in was $43.9 \%$ and median survival time was 32.3 months. On multivariate analysis, the endometrial subtype of $\mathrm{OC}$ and serum $\mathrm{CA} 125<12.5 \mathrm{U} / \mathrm{ml}$ at the end of treatment were independent, positive prognostic factors for 5-year overall survival.

Conclusion: Prognostic factors for favourable treatment outcomes in Polish patients with BRCA1-OC do not appear to differ from those in patients with sporadic OC. The incidence of the endometrial subtype of OC was relatively high (34.9\%) among women in the study. This was unexpected and has not been reported previously. This subtype of OC was an independent prognostic factor for favourable treatment outcomes.

Keywords: Ovarian cancer, BRCA1, Prognostic factors

\section{Background}

Many reports suggest that the outcomes of treatment for ovarian cancer $(\mathrm{OC})$ differ between patients who are carriers of $B R C A 1 / 2$ mutations and patients with sporadic OC (SOC). Most investigators report a better outcome for patients with BRCA1/2-dependent OC (BRCA1/2-OC).

\footnotetext{
* Correspondence: jerzy.mitus@gmail.com

${ }^{2}$ Department of Surgical Oncology, Centre of Oncology, Maria

Skłodowska-Curie Memorial Institute, Kraków Branch, ul. Garncarska 11,

31-115 Kraków, Poland

${ }^{3}$ Department of Anatomy, Collegium Medicum, Jagiellonian University, ul. Kopernika 12, 31-034 Kraków, Poland

Full list of author information is available at the end of the article
}

The BRCA1 and BRCA2 mutations are thought to cause an impaired ability to repair DNA damage, and as a result, BRCA1/2-OC is more sensitive than SOC to chemotherapeutic drugs that act directly on the DNA double helix, such as cisplatin and carboplatin $[1,2]$.

To date, most studies of the effect of BRCA1 and $B R C A 2$ mutations on OC treatment outcomes have been carried out among American, British and Ashkenazi Jewish women. The significance of germline mutation of the $B R C A 2$ gene in the Polish population has not yet been established and, unlike mutation of the BRCA1 gene, it is not routinely screened for among OC patients. Apart 
from one observational study in a small group of patients, there are no data on treatment outcomes for Central and Eastern European women with BRCA1-OC [3]. It is possible that genetic diversity might lead to different treatment outcomes in this population compared with previously studied populations. Moreover, there are limited data available on prognostic factors among patients with $B R C A 1-O C$ and it has not yet been determined whether prognostic factors in patients with $B R C A 1-\mathrm{OC}$ differ from those in patients with SOC. Therefore, the aim of this study was to analyse the prognostic factors for favourable treatment outcomes in Polish patients with BRCA1-OC.

\section{Methods}

The records of all patients with OC treated with surgery and chemotherapy at the Centre of Oncology in Kraków, Poland, from 2004 to 2009 were reviewed. In total, there were records for 1225 patients with OC diagnosed based on examination of the surgical specimen or biopsy. From the 1225 records, a group of 249 consecutive patients who fulfilled the criteria of high risk for hereditary OC based on family history were identified. After written, informed consent was obtained blood was collected from these 249 patients for BRCA1 mutation analysis. Exons 2, 5, 11 and 20 of the $B R C A 1$ gene were analysed, and the most frequent BRCA1 gene mutations among the Polish population were searched for: 4153delA, 5382insC C61G, 185delAG and 3819del5. The DNA analysis was carried out using denaturing high-performance liquid chromatography (dHPLC), restriction fragment length polymorphism (RFLP) and sequencing. The patients with BRCA1 mutations were selected as the study group. The study was approved by the Ethics Committee of Maria Skłodowska-Curie Memorial Institute.

Response to combination therapy (surgery and chemotherapy) used to treat BRCA1-OC was assessed based on clinical examination, imaging (Response Evaluation Criteria in Solid Tumors [RECIST] criteria 1.0) and marker analysis (serum CA125 concentration). Patients were evaluated every three months for 2 years and every 6 months thereafter. All patients in the study group were observed for at least 3 years or until death.

The effectiveness of treatment was evaluated according to time to progression, defined as the period between the beginning of treatment and clinical or imaging identification of recurrence of cancer, and 5-year overall survival from the beginning of treatment. The mean followup period was 65 months. Survival probability was estimated using the Kaplan-Meier method [4]. Peto's logrank test was used to assess the statistical significance of differences among the results [5]. The level of statistical significance was set at $p<0.05$. The Cox proportional hazards model was used to assess the impact of selected factors on patient survival [6].

\section{Results and discussion}

Among the 249 consecutive patients at high risk of hereditary $\mathrm{OC}$ who were screened for germline mutation of the BRCA1 gene, 69 (27.7 \%) had mutations. However, three women from this group did not complete the treatment and were excluded from the study (one refused chemotherapy and two died shortly after surgery without having completed adjuvant treatment). Therefore, the final study group included 66 patients with BRCA1-OC. Before beginning treatment, all patients had a histopathological diagnosis of OC. The median age was 49.5 years (mean 48 years, range 23-75 years). All study patients underwent planned combination therapy and were further observed. They received from three to nine courses of adjuvant therapy. Population, microscopic and clinical characteristics of the 66 patients with BRCA1-OC are presented in Table 1.

During follow-up, progression occurred in 48 (72.7 \%) of the study group. The mean time to progression was 26.2 months (median 20 months). The 5-year survival rate was $43.9 \%$ and the median survival time was 32.3 months. The overall survival Kaplan-Meier curve is presented in Fig. 1. Table 2 shows a comparison of the most significant publications on BRCA1/2-dependant OC in terms of survival.

The population, microscopic and clinical factors that were significant on univariate analysis are presented in Table 3. Multivariate analysis showed a positive, statistically significant impact of the endometrial subtype of OC and serum CA125 $(<12.5 \mathrm{U} / \mathrm{ml}$ at the end of treatment) on 5-year overall survival from BRCA1-OC. Both of these factors were independent prognostic factors for 5 -year overall survival (Table 4).

The composition of the study group did not differ from previously published studies in terms of population, histopathologic and clinical factors. The number of BRCA1-OC patients in the present study was relatively high compared to previous studies, most of which included 13-43 patients, with only a few recruiting higher numbers of 88-245 patients. Among these previous studies, a small number evaluated the clinical features and outcome of patients with BRCA1-OC separately from patients with $B R C A 2-O C$. However, these studies were conducted among Jewish, American and Western European populations, which seem to be genetically different from the Polish population [7-9].

Consistent with previous reports, the serous subtype of OC was predominant among the study patients $(n=$ $27,40.9 \%)$. The percentage of the serous subtype reported in the literature varies widely from 25 to $93 \%$, which might be related to the size of patient groups. However, in contrast to previous reports, the percentage of patients with the endometrial subtype of OC (34.9\%) was high in the present study, whereas previous studies 
Table 1 Population, microscopic and clinical characteristics of BRCA1-OC patients

\begin{tabular}{|c|c|c|c|c|c|}
\hline \multirow{3}{*}{ Population, microscopic and clinical characteristics } & \multirow{3}{*}{$\begin{array}{l}\text { No. of } \\
\text { patients } \\
66\end{array}$} & \multirow{3}{*}{$\begin{array}{l}\text { Percent } \\
100\end{array}$} & \multirow[b]{2}{*}{ - interval } & \\
\hline & & & & 22 & 33.3 \\
\hline & & & \multicolumn{3}{|l|}{ The overall extent of cytoreduction } \\
\hline \multicolumn{3}{|l|}{$\overline{\text { Age }}$} & \multirow{2}{*}{$\begin{array}{l}\text { - optimal } \\
\text { - suboptimal }\end{array}$} & 34 & 51.5 \\
\hline \multirow{2}{*}{$\begin{array}{l}-\leq 50 \text { years } \\
->50 \text { years }\end{array}$} & 34 & 51.5 & & 32 & 48.5 \\
\hline & 32 & 48.5 & $\begin{array}{l}\text { The average concentration of CA125 at the } \\
\text { beginning of treatment }\end{array}$ & \multicolumn{2}{|l|}{$\begin{array}{l}1113 \mathrm{U} / \\
\mathrm{ml}\end{array}$} \\
\hline \multicolumn{3}{|l|}{ Menopause } & \multirow{2}{*}{$\begin{array}{l}\text { The average concentration of CA125 at the end of } \\
\text { treatment }\end{array}$} & \multirow[t]{2}{*}{$71 \mathrm{U} / \mathrm{ml}$} & \\
\hline - yes & 28 & 42.4 & & & \\
\hline
\end{tabular}

No. of births

$-0$

$-1$

$-\geq 2$

Family history

- 1st degree relatives with ovarian cancer

- 1st degree relatives with breast cancer

Coexisting breast cancer

- yes

Type of BRCA1 gene mutation

-C61G

- 5382insC

- 4153delAG

- 189delAG

- 3819del5

- IVS20 + 60ins 12

$-4158 \mathrm{~A}>\mathrm{G}$

Grading of the tumor

- G1

$-G 2$

$-\mathrm{G} 3$

Histological type

- serous

- endometrial

- undifferentiated

- mucous

- clear cell

- mezonefroid

Staging FIGO (2009)

$-1$

$-\|$

- III

- IV

Cytoreduction

- primary
Table 1 Population, microscopic and clinical characteristics of BRCA1-OC patients (Continued)

have found that $14 \%$ or less of patients with BRCA1OC have this subtype [10]. Interestingly, another Polish population analysis of patients with $B R C A 1-\mathrm{OC}$ reported an unusually high percentage of mucinous cancers $(17 \%)$. However, that study was small with only 18 patients [3]. Both findings are unusual because somatic tumour mutations of the BRCA1 gene are rare in endometrial and mucinous subtypes of $\mathrm{OC}$.

\section{Prognostic factors in patients with $B R C A 1-O C$}

To date, few studies have investigated prognostic factors associated with BRCA1/2-OC. Most research has focussed on differences in treatment outcomes between OC patients with and without $B R C A 1 / 2$ mutations. Furthermore, few studies have looked at differences in prognostic factors between patients with SOC and BRCA1/2-OC.

The strongest prognostic factor for treatment outcomes in patients with SOC is the FIGO cancer stage. On univariate analysis in the present study, the FIGO cancer stage was a prognostic factor for 5-year overall survival of BRCA1-OC patients. However, this was not confirmed in the multivariate analysis, possibly as a result of the small number of patients with early-stage disease (4 patients had stage I disease and 8 had stage II disease).

Similar to SOC patients, in the present study optimal surgical cytoreduction (remnants after surgery $\leq 1 \mathrm{~cm}$ ) had a positive prognostic impact on survival in patients with BRCA1-OC. The difference in the 5year survival rate between patients with and without optimal surgical cytoreduction was $30 \%$, which is similar to that reported in the literature for SOC $[11,12]$. Only one previous study investigated the impact of the extent of surgical cytoreduction on survival in patients with $B R C A 1 / 2-O C$ [10]. That study identified a statistically significant higher risk of death among patients with surgery that was not considered complete, with a hazard ratio $(\mathrm{HR})=1.48$ on multivariate analysis. However, in the present study, the prognostic value of cytoreduction was not confirmed on multivariate analysis, probably because of the limited number of cases. 


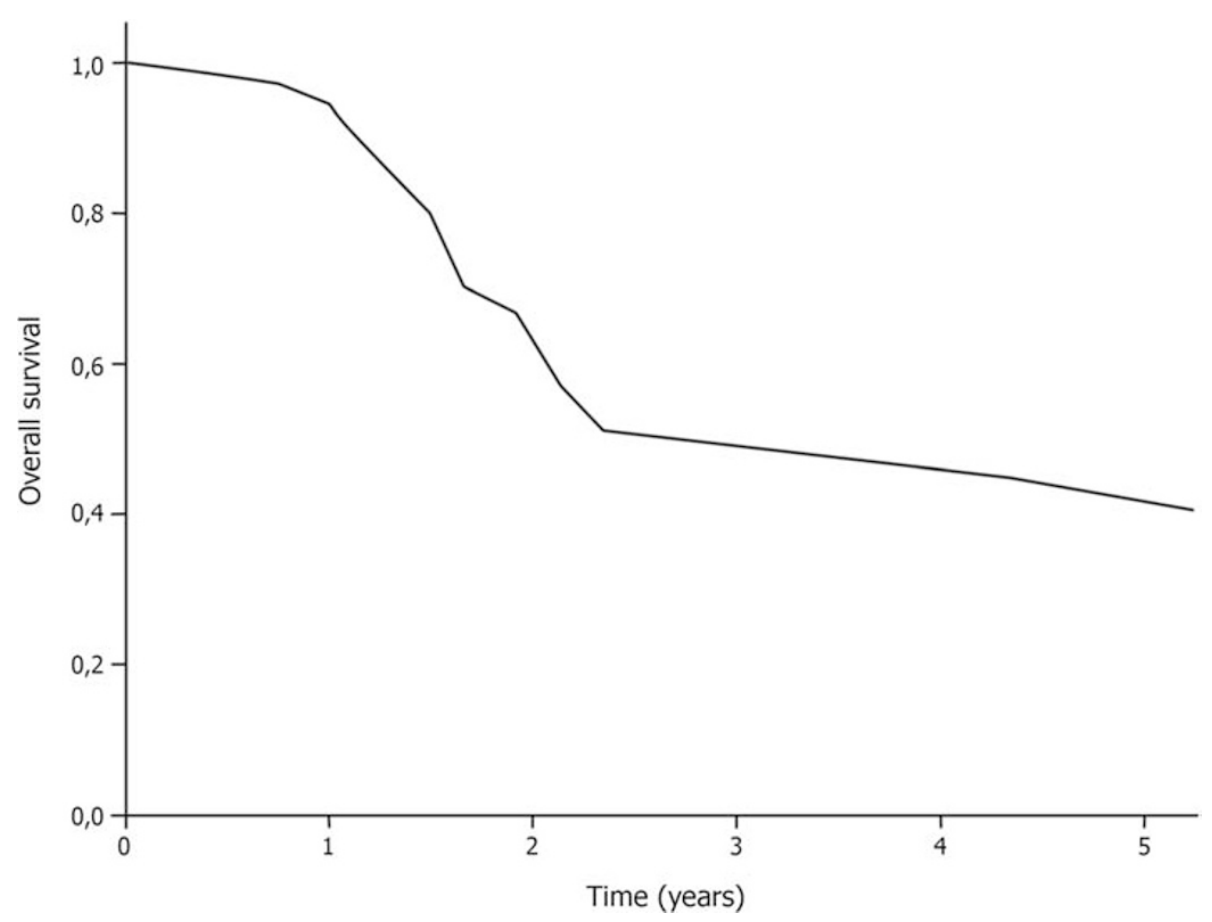

Fig. 1 Overall survival of patients with BRCA1-OC

Of the patients with BRCA1-OC in the present study, nine $(13.6 \%)$ patients had been previously treated for breast cancer, and had achieved a complete and long-lasting remission. In all nine patients, the breast cancer was treated with surgery and one line of anthracycline-based chemotherapy. None of the patients had received platinum agents. Imaging, clinical findings, serum markers and immunohistochemical analysis of ovarian tumours confirmed that all nine patients had primary OC rather than secondary breast cancer. The 5-year survival rate in this group was significantly lower compared with the other BRCA1-OC patients $(11.1 \%$ vs. $49.1 \%$, respectively). It should be noted that progression of OC can mask the recurrence of breast cancer resulting in poorer outcomes.

Table 2 Comparison of long-term outcome in patients with BRCA-OC

\begin{tabular}{|c|c|c|c|c|}
\hline Author, year of publication & No. of patients & Population & Overall 5-year survival & Median survival \\
\hline Rubin 1996 [23] & 53 & BRCA1/2-OC & $\sim 60 \%^{\mathrm{a}}$ & $\sim 80$ months $^{a}$ \\
\hline Pharoah 1999 [7] & 127 & BRCA1/2-OC & $21 \%$ & 20,6 months \\
\hline Boyd 2000 [10] & 67 & BRCA1-OC & $\sim 50 \%^{\mathrm{a}}$ & $\sim 60$ months $^{a}$ \\
\hline Ramus 2001 [24] & 15 & BRCA1-OC & $\sim 25 \%^{\mathrm{a}}$ & 52 months \\
\hline Cass 2003 [11] & 33 & BRCA1/2-OC & $65 \%$ & 91 months \\
\hline Majdak 2005 & 18 & BRCA1-OC & $\sim 33 \%^{\mathrm{a}}$ & $\sim 28$ months $^{a}$ \\
\hline Chetrit 2008 [8] & 213 & BRCA1/2-OC & $46 \%$ & 53,7 months \\
\hline Tan 2008 [25] & 22 & BRCA1/2-OC & $\sim 65 \%^{\mathrm{a}}$ & 8,4 years \\
\hline Kringen 2005 [26] & 30 & BRCA1/2-OC & $33,3 \%$ & - \\
\hline Lacour 2011 [27] & 95 & BRCA1/2-OC & $\sim 25 \%^{\mathrm{a}}$ & 101,7 months \\
\hline Hyman 2012 [9] & 30 & BRCA1-OC & $\sim 60 \%{ }^{\mathrm{a}}$ & 6 years \\
\hline Vencken 2013 [28] & 245 & $B R C A 1-O C$ & $62 \%$ & 6 years \\
\hline Bolton 2012 [29] & 909 & $B R C A 1-O C$ & $44 \%$ & 4,6 years \\
\hline Own material & 66 & $B R C A 1-O C$ & $43,9 \%$ & 32,3 months \\
\hline
\end{tabular}

\footnotetext{
a Data extrapolated from the Kaplan-Meier curves
}

${ }^{b}$ Polish patients population 
Table 3 Results of treatment of patients with BRCA1-OC depending on the population, microscopic and clinical characteristics

\begin{tabular}{|c|c|c|c|}
\hline \multirow[t]{2}{*}{$\begin{array}{l}\text { Population, microscopic and } \\
\text { clinical characteristics }\end{array}$} & \multirow[t]{2}{*}{$\begin{array}{l}\text { No. of } \\
\text { patients }\end{array}$} & \multicolumn{2}{|c|}{$\begin{array}{l}5 \text {-year overall } \\
\text { survival }\end{array}$} \\
\hline & & $\begin{array}{l}\text { No. of } \\
\text { patients }\end{array}$ & $\%$ \\
\hline $\begin{array}{l}\text { The number of patients with BRCAl } \\
\text { gene mutation }\end{array}$ & 66 & 29 & 43.9 \\
\hline \multicolumn{4}{|l|}{${ }^{a}$ Coexisting neoplasms } \\
\hline- no & 57 & 28 & 49.1 \\
\hline - breast cancer & 9 & 1 & 11.1 \\
\hline \multicolumn{4}{|l|}{${ }^{a}$ The total extent of cytoreduction } \\
\hline - optimal & 34 & 20 & 58.8 \\
\hline - suboptimal & 32 & 9 & 28.1 \\
\hline \multicolumn{4}{|l|}{ a Staging FIGO (2009) } \\
\hline-1 & 4 & 4 & 100.0 \\
\hline$-\|$ & 8 & 5 & 62.5 \\
\hline$-\mid I I$ & 50 & 19 & 38.0 \\
\hline- IV & 4 & 1 & 25.0 \\
\hline \multicolumn{4}{|l|}{${ }^{a}$ Histological type } \\
\hline - serous & 27 & 11 & 40.7 \\
\hline - endometrial & 23 & 14 & 60.9 \\
\hline - undifferentiated & 8 & 1 & 12.5 \\
\hline - mucous & 4 & 2 & 50.0 \\
\hline - clear cell & 2 & 1 & 50.0 \\
\hline - mezonefroid & 2 & 0 & 0 \\
\hline \multicolumn{4}{|l|}{$\begin{array}{l}{ }^{a} \text { CA125 concentration at the beginning } \\
\text { of treatment }\end{array}$} \\
\hline$-<285,5$ & 31 & 21 & 67.7 \\
\hline$-\geq 285,5$ & 35 & 8 & 22.9 \\
\hline \multicolumn{4}{|l|}{$\begin{array}{l}{ }^{a} \text { CA } 125 \text { concentration at the end } \\
\text { of treatment }\end{array}$} \\
\hline$-<12,5$ & 34 & 22 & 64.7 \\
\hline$-\geq 12,5$ & 22 & 7 & 31.8 \\
\hline
\end{tabular}

a Statistically significant differences, log rank test, $p<0.05$

Among patients with BRCA1-OC, Chetrit et al. found that the serous subtype of $\mathrm{OC}$ was associated with a poorer prognosis compared to the non-serous subtype (5-year overall survival rate of $44.9 \%$ vs. $50 \%$, respectively), and poorly differentiated tumours were associated with a poorer prognosis than well differentiated and moderately differentiated subtypes (5year overall survival rate of $45.4 \%$ vs. $55 \%$, respectively) [8]. In terms of the importance of microscopic subtypes of $\mathrm{OC}$ on prognosis, the results of the present study agreed with previous studies on SOC. On univariate analysis the endometrial subtype of OC was associated with a better prognosis compared to the serous subtype of $\mathrm{OC}$, and the poorest prognosis was associated with the undifferentiated adenocarcinoma subtype. The numbers of patients in the present study with mucous, clear-cell and mesonephroid types of BRCA1-OC were too small to draw statistical conclusions. Endometrial tumours are more likely to develop in the pelvis without spread to the upper abdomen and they are more likely to be diagnosed at an early stage. Similarly, on multivariate analysis, a statistically significant positive impact on the 5-year overall survival was associated with the endometrial subtype of the OC. The impact of histological grade (G) on treatment outcomes was not statistically significant on univariate or multivariate analysis.

The serum CA125, both at the beginning of treatment and after treatment completion, is a widely confirmed prognostic factor in patients with OC [13-20]. For patients with BRCA1-OC, the reported average serum CA125 before treatment ranges from $445 \mathrm{U} / \mathrm{ml}$ to 824 $\mathrm{U} / \mathrm{ml}[11,21,22]$. However, there are no data on serum CA125 levels at the end of treatment. In the present study, the average serum CA125 in patients with BRCA1-OC was $113 \mathrm{U} / \mathrm{ml}$ and $71 \mathrm{U} / \mathrm{ml}$ before and after treatment, respectively. No previous studies have reported that serum CA125 levels were a prognostic factor in patients with $B R C A 1 / 2-O C$. However, on univariate analysis in the present study a relatively low serum CA125 at the beginning of treatment and after treatment was associated with better prognosis $(67.7 \%$ vs. $22.9 \%$ 5 -year overall survival for serum CA125 $\leq 285.5 \mathrm{U} / \mathrm{ml}$ vs. $>285.5 \mathrm{U} / \mathrm{ml}$ at the beginning of treatment, and $64.7 \%$ vs. $31.8 \% 5$-year overall survival for serum CA125 of $\leq 12.5 \mathrm{U} / \mathrm{ml}$ vs. $>12.5 \mathrm{U} / \mathrm{ml}$ after treatment).

\section{Conclusions}

Prognostic factors for treatment outcomes in Polish patients with BRCA1-OC do not appear to differ from

Table 4 Results of the multivariate analysis of prognostic factors in the group of 66 patients with BRCA1-OC

\begin{tabular}{|c|c|c|c|c|}
\hline Variable & Variant & Relative risk (RR) & Confidence interval & $p$ value \\
\hline \multirow[t]{2}{*}{ Histological type } & Undifferentiated adenocarcinoma & 39,29 & $2,07-743,35$ & $p=0.014$ \\
\hline & Serous adenocarcinoma & 1 & & \\
\hline \multirow[t]{2}{*}{ Histological type } & Endometrial adenocarcinoma & 0,2 & $0,04-0,85$ & $p=0.03$ \\
\hline & Serous adenocarcinoma & 1 & & \\
\hline Level of CA125 at the end of treatment & $<12,5 \mathrm{U} / \mathrm{ml}$ & 0,23 & $0,07-0,69$ & $p=0.01$ \\
\hline
\end{tabular}


those in patients with SOC. The incidence of the endometrial subtype of $\mathrm{OC}$ was relatively high, which is a new finding not previously reported in the literature. This form of OC was also an independent, positive prognostic factor on multivariate analysis.

\section{Competing interests}

The authors declare that they have no competing interests.

\section{Authors' contributions}

All authors participated in the design, coordination, interpretation and critical revision of the manuscript. WS and PBL made substantial contributions to the conception and design of the study. JWM, MJ, Et and WS were involved in patient care and clinical data collection. WS, PBL, JJ, Et and TB wrote the manuscript. TB performed the molecular analysis. PBL, JWM, JJ, and MJ performed the statistical analysis. All authors read and approved the final manuscript.

\section{Author details}

'Department of Gynaecological Oncology, Centre of Oncology, Maria Skłodowska-Curie Memorial Institute, Kraków Branch, ul. Garncarska 11, 31-115 Kraków, Poland. 'Department of Surgical Oncology, Centre of Oncology, Maria Skłodowska-Curie Memorial Institute, Kraków Branch, ul. Garncarska 11, 31-115 Kraków, Poland. ${ }^{3}$ Department of Anatomy, Collegium Medicum, Jagiellonian University, ul. Kopernika 12, 31-034 Kraków, Poland. ${ }^{4}$ Department of Medical Oncology, Centre of Oncology, Maria Skłodowska-Curie Memorial Institute, Kraków Branch, ul. Garncarska 11, 31-115 Kraków, Poland. ${ }^{5}$ Department of Radiology, Centre of Oncology, Maria Skłodowska-Curie Memorial Institute, Kraków Branch, ul. Garncarska 11, 31-115 Kraków, Poland. 'Department of Radiotherapy, Centre of Oncology, Maria Skłodowska-Curie Memorial Institute, Kraków Branch, ul. Garncarska 11, 31-115 Kraków, Poland. ${ }^{7}$ Department of Genetics and Pathology, International Hereditary Cancer Center and Clinic of Oncology Pomeranian Medical University, Szczecin, ul. Połabska 4, 70-115 Szczecin, Poland.

\section{Received: 7 May 2015 Accepted: 7 October 2015}

\section{(1)}

\section{References}

1. Byrski T, Dent R, Blecharz P, Foszczynska-Kloda M, Gronwald J, Huzarski T, et al. Results of a phase II open-label, non-randomized trial of cisplatin chemotherapy in patients with BRCA1-positive metastatic breast cancer. Breast Cancer Res. 2012:14(4):R110. doi:10.1186/bcr3231.

2. Dann RB, DeLoia JA, Timms KM, Zorn KK, Potter J, Flake 2nd DD, et al. BRCA1/2 mutations and expression: response to platinum chemotherapy in patients with advanced stage epithelial ovarian cancer. Gynecol Oncol. 2012;125(3):677-82. doi:10.1016/j.ygyno.2012.03.006.

3. Majdak EJ, Debniak J, Milczek T, Cornelisse CJ, Devilee P, Emerich J, et al. Prognostic impact of BRCA1 pathogenic and BRCA1/BRCA2 unclassified variant mutations in patients with ovarian carcinoma. Cancer. 2005;104(5): 1004-12. doi:10.1002/cncr.21276.

4. Kaplan EL, Meier P. Nonparametric estimation from incomplete observations. J Am Stat Assoc. 1958;53:457-81

5. Peto R, Pike MC, Armitage P, Breslow NE, Cox DR, Howard SV, et al. Design and analysis of randomized clinical trials requiring prolonged observation of each patient. II. analysis and examples. Br J Cancer. 1977;35(1):1-39.

6. Cox DR. Regression models and life-tables (with discussion). Br J Cancer. 1977;35(1):1-39.

7. Pharoah PD, Easton DF, Stockton DL, Gayther S, Ponder BA. Survival in familial, BRCA1-associated, and BRCA2-associated epithelial ovarian cancer. United Kingdom Coordinating Committee for Cancer Research (UKCCCR) Familial Ovarian Cancer Study Group. Cancer Res. 1999:59(4):868-71.

8. Chetrit A, Hirsh-Yechezkel G, Ben-David Y, Lubin F, Friedman E, Sadetzki S. Effect of BRCA1/2 mutations on long-term survival of patients with invasive ovarian cancer: the national Israeli study of ovarian cancer. J Clin Oncol. 2008;26(1):20-5. doi:10.1200/JCO.2007.11.6905.

9. Hyman DM, Zhou Q, lasonos A, Grisham RN, Arnold AG, Phillips MF, et al. Improved survival for BRCA2-associated serous ovarian cancer compared with both BRCA-negative and BRCA1-associated serous ovarian cancer. Cancer. 2012;118(15):3703-9. doi:10.1002/cncr.26655.
10. Boyd J, Sonoda Y, Federici MG, Bogomolniy F, Rhei E, Maresco DL, et al. Clinicopathologic features of BRCA-linked and sporadic ovarian cancer. JAMA. 2000;283(17):2260-5.

11. Cass I, Baldwin RL, Varkey T, Moslehi R, Narod SA, Karlan BY. Improved survival in women with BRCA-associated ovarian carcinoma. Cancer. 2003; 97(9):2187-95. doi:10.1002/cncr.11310.

12. Eisenkop SM, Spirtos NM, Friedman RL, Lin WC, Pisani AL, Perticucci S. Relative influences of tumor volume before surgery and the cytoreductive outcome on survival for patients with advanced ovarian cancer: a prospective study. Gynecol Oncol. 2003;90(2):390-6.

13. Han LY, Karavasilis V, Hagen T, Nicum S, Thomas K, Harrison M, et al, Doubling time of serum CA125 is an independent prognostic factor for survival in patients with ovarian cancer relapsing after first-line chemotherapy. Eur J Cancer. 2010;46(8):1359-64. doi:10.1016/j.ejca.2010.02.012.

14. Ferrandina G, Ludovisi M, Corrado G, Carone V, Petrillo M, Scambia G. Prognostic role of Ca125 response criteria and RECIST criteria: analysis of results from the MITO-3 phase III trial of gemcitabine versus pegylated liposomal doxorubicin in recurrent ovarian cancer. Gynecol Oncol. 2008; 109(2):187-93. doi:10.1016/j.ygyno.2008.01.039.

15. Meier W, Stieber P, Hasholzner U, Gropp M, Fateh-Moghadam A. Prognostic significance of CA125 in patients with ovarian cancer and secondary debulking surgery. Anticancer Res. 1997:17(4B):2945-7.

16. Alvarez RD, To A, Boots $L R$, Shingleton HM, Hatch $K D$, Hubbard J, et al. CA125 as a serum marker for poor prognosis in ovarian malignancies. Gynecol Oncol. 1987;26(3):284-9.

17. Jeyarajah $A R$, Ind TE, MacDonald N, Skates S, Oram DH, Jacobs IJ. Increased mortality in postmenopausal women with serum CA125 elevation. Gynecol Oncol. 1999;73(2):242-6. doi:10.1006/gyno.1999.5350.

18. Akahira Jl, Yoshikawa H, Shimizu Y, Tsunematsu R, Hirakawa T, Kuramoto H, et al. Prognostic factors of stage IV epithelial ovarian cancer: a multicenter retrospective study. Gynecol Oncol. 2001;81(3):398-403. doi:10.1006/gyno. 2001.6172.

19. Guppy AE, Nelstrop AE, Foster T, Agarwal R, Seckl MJ, Rustin GJ. A phase II study of sequential carboplatin, paclitaxel and topotecan in patients with previously untreated advanced ovarian cancer. Br J Cancer. 2004;90(4):810-4. doi:10.1038/sj.bjc.6601618.

20. Gardner GJ, Baser RE, Brady MF, Bristow RE, Markman M, Spriggs D, et al. CA125 regression in ovarian cancer patients treated with intravenous versus intraperitoneal platinum-based chemotherapy: a gynecologic oncology group study. Gynecol Oncol. 2012;124(2):216-20. doi:10.1016/j.ygyno.2011.10.021.

21. Buller RE, Shahin MS, Geisler JP, Zogg M, De Young BR, Davis CS. Failure of BRCA1 dysfunction to alter ovarian cancer survival. Clin Cancer Res. 2002;8(5):1196-202.

22. Gallagher DJ, Konner JA, Bell-McGuinn KM, Bhatia J, Sabbatini P, Aghajanian $C A$, et al. Survival in epithelial ovarian cancer: a multivariate analysis incorporating BRCA mutation status and platinum sensitivity. Ann Oncol. 2011;22(5):1127-32. doi:10.1093/annonc/mdq577.

23. Rubin SC, Benjamin I, Behbakht K, Takahashi H, Morgan MA, LiVolsi VA, et al. Clinical and pathological features of ovarian cancer in women with germ-line mutations of BRCA1. N Engl J Med. 1996;335(19):1413-6.

24. Ramus SJ, Fishman A, Pharoah PD, Yarkoni S, Altaras M, Ponder BA, et al. Ovarian cancer survival in Ashkenazi Jewish patients with BRCA1 and BRCA2 mutations. Eur J Surg Oncol. 2001;27(3):278-81.

25. Tan DS, et al. "BRCAness" syndrome in ovarian cancer: a case-control study describing the clinical features and outcome of patients with epithelial ovarian cancer associated with BRCA1 and BRCA2 mutations. J Clin Oncol. 2008;26(34):5530-6.

26. Kringen P, Wang Y, Dumeaux V, Nesland JM, Kristensen G, Borresen-Dale AL, et al. TP53 mutations in ovarian carcinomas from sporadic cases and carriers of two distinct BRCA1 founder mutations; relation to age at diagnosis and survival. BMC Cancer. 2005;5:134.

27. Lacour RA, Westin SN, Meyer LA, Wingo SN, Schorge JO, Brooks R, et al. Improved survival in non-Ashkenazi Jewish ovarian cancer patients with BRCA1 and BRCA2 gene mutations. Gynecol Oncol. 2011;121(2):358-63.

28. Vencken PM, Reitsma W, Kriege M, Mourits MJ, de Bock GH, de Hullu JA, et al. Outcome of BRCA1- compared with BRCA2-associated ovarian cancer: a nationwide study in the Netherlands. Ann Oncol. 2013;24(8):2036-42.

29. Bolton KL, Chenevix-Trench G, Goh C, Sadetzki S, Ramus SJ, Karlan BY, et al. Association between BRCA1 and BRCA2 mutations and survival in women with invasive epithelial ovarian cancer. JAMA. 2012;307(4):382-90. 